\title{
EDITORIAL
}

\section{Educação tutorial: vivências e aprendizagem}

Esta edição especial da REFACS destaca entre outras, a produção de conhecimento envolvendo o processo formativo do graduando do curso de Enfermagem, em especial membros do Programa de Educação Tutorial (PET-Enfermagem), bem como de pós-graduandos na formação em serviço dos Programas de Residências em Saúde do Hospital de Clínicas da Universidade Federal do Triângulo Mineiro (HC/UFTM).

Os relatos de experiências dos graduandos do PET-Enfermagem foram desenvolvidos em atividades extracurriculares, por meio de ensino-aprendizagem baseado na metodologia ativa e descritiva, considerando as reflexões dos estudantes sobre os diversos projetos de ensino e extensão. Estes relatos possibilitaram a aproximação com a pesquisa, fomentando um ambiente estimulante para o processo ensino aprendizagem imprescindível para a formação e a atuação profissional. Esta base de ensino impregna aspectos da democratização do acesso aos diversos programas de formação para consideração valorativa dos talentos individuais e coletivos, devendo ser desenvolvidos para a construção de uma sociedade mais justa e coesa.

Essas experiências abordam diferentes temáticas, permitindo a compreensão ampliada, como por exemplo: o empoderamento dos usuários dos serviços de saúde quanto ao seus direitos e deveres; aprendizagem significativas nos diferentes cenários dessas práticas e suas relações entre cidadania, participação popular e políticas públicas de saúde a partir da participação no Conselho Municipal de Saúde, ou quanto a busca constante do estudante por conhecimento abrangentes e coerentes, não considerados na grande curricular, a partir da proposição de temas trabalhados no formato de minicursos.

Outras vivencias também se destacam: o construcionismo relacional envolvendo os discentes de enfermagem na recepção e integração de novos ingressantes no curso; a literacia em saúde acerca da compreensão e avaliação crítica de informações sobre saúde que possam apoiar a tomada de decisão difundidas nos meios de comunicação (como jornal impresso e rádio); a teoria de comunicação em massa com vistas a mobilização e engajamento dos graduandos, no planejamento e trabalho em grupo, na organização e desenvolvimento de evento no âmbito da saúde do homem; além da, comunicação estratégica de caráter multiprofissional e interdisciplinar, participantes (docentes, comunidade e estudantes) contribuindo com a formação de cidadãos critico ético e reflexivo, o que repercute resultados positivos no contexto da sociedade.

Os resultados ora apresentados procuram romper com o modelo tradicional de ensino baseado em conteúdos curriculares pré-estabelecidos, abrindo um espaço de diálogos e formação de diferentes saberes, ampliando os canais de aprendizagem, percepção e participação do estudante numa reflexão crítica orientada pela cidadania e pela função social da educação superior

É possível a partir dessas experiências observar que a constituição relacional dos estudantes tenham maior embasamento para enfrentar os desafios da formação e inserção no mundo do trabalho,

Boa Leitura!

Divanice Contim

Enfermeira. Mestre e Doutora em Enfermagem. Professora Associada da Universidade Federal do Triângulo Mineiro UFTM.

Gilberto de Araújo Pereira

Estatístico. Mestre e Doutor em Estatística. Professor Adjunto e coordenador do PET Enfermagem da UFTM. 